Bachman | Pedersen Zari | Enright | Lyn : Dulaney | Neveu

Kim | Bachman | Fisher : Hayes : Feldman: Grondzik

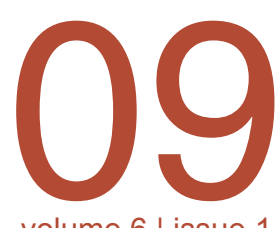

volume 6 | issue 1

\section{Affecting Change in Architectural Education}

\author{
Leonard Bachman, The University of Houston-Central \\ Christine Bachman, The University of Houston-Downtown
}

This reliance on an argumentative and implicit knowledge base as the generator of architectural pedagogy has been arguably quite successful to date. It is after all, self replicating and serves to regenerate and repopulate the profession. Our studio-based problem-solving approach even seems to have anticipated higher education's recent turn to active learning, student centered learning and other such worthwhile evolutions. The problem however is that this mismatch of architecture-as-topic with education-as-medium has left the compound verb of architecturaleducation stuck in a self-referential, unreflective, and self-satisfied state. Critique of the existing paradigm is mostly hushed. Change has been very difficult and very slow in this realm of education, and progress based on empirical evidence is almost non-existent. This volume of the ARCC Journal investigates how that situation might be changed.

And things are changing. As the opening quote suggests, architectural education is a living thing and its growth connotes change. The problematic conflation of architectural knowing with architectural teaching is increasingly being challenged. In the Kuhnian sense, the paradigm has already eroded. The world we serve is changing, the profession is changing, and education is changing. Consequently, some fundamental precepts of architectural education are changing too.

Roots of this transformation grow from the fertile soil of postindustrial society and our knowledge-based production of value. Evidence trumps argument, just as nutrition must trump cuisine even though they are not mutually exclusive. The culture of argument which forms the discourse of architectural critique is being usurped on many fronts by the rising culture of evidence. Critical argument is of course well suited to the complex and sublime nature of design as an activity and it works well as an intersubjective measure-by-agreement. Some radical reorientation is however, needed to adapt it to our current best practice knowledge about evidence based teaching and learning. The topic and the medium need realignment.

The forces for change are many and mounting. The laundry list is long, but here are some high points:

- Current writings on the basis of creativity often contradict strategies used in the mainstream of design studio learning

- Research on what constitutes a coherent curriculum differs from the typical studio-centric nature of architecture schools 
- Pressures to engage a systematic and empirical process of operationalizing and then measuring student learning outcomes are emerging in the postindustrial era of evidence based learning and university level accreditation standards

- The collateral organizations of architectural education in both the US and the UK are at a point of change. In 2008 alone, major conferences and institutional studies were held to "reconsider architectural education," and to rework the basis of accreditation standards... witness the 2009 NAAB Conditions

- Educational practice is becoming more learning outcome driven and less teacher centered; evidence of good teaching is meaningless unless supported by evidence of corollary student learning

- Educational technology is increasingly prevalent in all aspects of learning; not only is the access to information vastly expanded, but the ability to experience other places and interact with people outside the academy is broadly enhanced

- Studio culture summits have been held in the US and UK to reexamine the strengths and weaknesses of studio education, and to move the agenda forward on healthier habits and positive learning environment, as well as time and workload management

- Issues such as climate change and social justice are in competition with the cultural based drivers of traditional architecture as a design ethic, and the social issues are winning out

- Professional practice is merging previously separate design protocols. Sustainable Design, Building Information Modeling, and Integrated Practice are combining formal design with continuous performal evaluation... and the profession is looking to the schools to be part of the transition

Assuming that any meaningful portion of the above reasoning is on target, the opportunity to affect positive change in architectural education is at hand. Equally significant is the opportunity to embed a culture of continual refinement based on empirical evidence. Given the inertia of outside forces, this new culture seems inevitable. It would be far better if architectural educators were to engage this transformation proactively by using their own model of critique and discourse, mixed with a bit of objectivity borrowed from the postindustrial knowledge society in which they are now situated.

This issue of the ARCC Journal provides and promotes discourse on those issues. Content includes five peer reviewed papers on the topic, and an invited article on the design of learning outcomes. This issue concludes with panel discussion with four important voices each expressing critical perspectives on the theme of change in architectural education.
The peer reviewed articles lead off with "Changes in Climate Driving Changes in Architectural Education" by Maibritt Pedersen Zari (School of Architecture, Victoria University, Wellington, New Zealand) relating the transition of one school of architecture into "the world's first carbon neutral Faculty of Architecture." The second article is by John Enright (University of Southern California), "Applications in Cross-curriculum Teaching: The Synthesis of the Design Studio and Building Technology Seminar," involving a case of integrated technology and studio curriculum set in a matrix of teamwork and 3-D software. This is followed by "A Case for Drawing," by Francis Lyn (Florida Atlantic University) and Ron Dulaney (West Virginia University), who make qualitative and quantitative arguments for hand drawing versus digital media. The fourth peer reviewed article is by Marc J. Neveu (California Polytechnic State University, San Luis Obispo) "Educating the Reflexive Practitioner," which makes a case for Socratic teaching in architecture. We also note that Marc is a former recipient of the ARCC King Medal. The fifth and final peer reviewed paper is by Joongsub Kim, "Urban Design as a Catalyst for Advancing Architectural Education," which proposes the many different contingencies of urbanism as a means of informing design perspectives and setting a framework for architectural educational in general. 